\title{
Hablar desde el silencio: El silencio como verdad en las narrativas de mujeres sobrevivientes
}

\section{Resumen}

A partir del estudio de testimonios y entrevistas personales con ex detenidas-desaparecidas de la última dictadura militar en Argentina sostengo que, si bien todos los testimonios del horror están impregnados de la presencia del silencio, los testimonios de mujeres contienen dos aspectos fundamentales que los distinguen de otros. El primero es que sugieren una diferencia importante entre dos tipos de silencios, uno mudo y otro elocuente. $Y$ el segundo es que convocan a un interlocutor capaz de escuchar sus silencios. La mujeres asociadas históricamente con el silencio, se presentan como las indicadas para hacer de este no lo opuesto al lenguaje, sino el lenguaje mismo como lenguaje del trauma, invitándonos a leer el silencio, a descifrarlo, a leer más allá de las palabras, a entrenar el oído para escuchar aquellas verdades subjetivas, aceptando la imposibilidad de capturar el significado de estas experiencias del horror en su totalidad. Sin embargo, esta dificultad no implica una parálisis, un punto final, sino que sugieren "trabajar" ese silencio, agregándole valor, con el fin de transformar tanto la identidad de la víctima como la de la sociedad misma, creando oyentes empáticos y nuevos modos de ciudadanía.

Palabras claves

Testimonio, memoria, Argentina, género, trauma.

\begin{abstract}
Through the study of testimonial texts and personal interviews of women survivors of the last dictatorship in Argentina, I argue that while all testimonies of horror are permeated by the presence of silence, women's testimonial productions present two important aspects that differentiate them from other testimonies. The first one is that they suggest a difference between two types of silences in their narratives, one that is mute and another one that is eloquent. The second aspect these testimonies present is a call for the receptor to be able to hear these eloquent silences. Women-historically associated with silence- are the ones capable of speaking from within the silence, making this not the opposite of language, but the language itself as the language of trauma. Their accounts invite us to explore the silences, to decipher and to read what lies beyond words, training our ears to hear these unspeakable truths. However, accepting the impossibility of representing these horror-filled experiences does not mean to put an end to the
\end{abstract}


debate, on the contrary, it means to work and elaborate these silences in order to transform both the victim's identity and the society itself in order to create empathetic listeners and new modes of citizenship.

Keywords Testimony, memory, Argentina, genre, trauma.

It has a history, a form

Do not confuse it with any kind of absence. "Cartographies of Silence” Adrienne Rich

El vigor de la memoria solo puede sostenerse alli donde hay silencio [...] Aprender de memoria, transcribir fielmente, leer de verdad significa estar en silencio y en el interior del silencio.

George Steiner

El filósofo alemán Walter Benjamin en su ensayo El Narrador (1936) denunciaba la desaparición de la figura del narrador como consecuencia del fracaso de la experiencia como saber transmisible. Según Benjamin los soldados de la Primera Guerra Mundial volvían mudos de los campos de batalla: "la gente volvía [...] no más rica, sino más pobre en experiencia comunicable" (Benjamin 112). De este modo, Benjamin establecía una relación entre el lenguaje (o falta de lenguaje) y las experiencias del horror. Lo acontecido en las trincheras durante la Primera Guerra Mundial supuso una ruptura con la tradición narrativa, en tanto la experiencia sufrida ya no podía ser transmitida. Décadas más tarde, haciendo referencia a los mecanismos de deshumanización y exterminio llevados a cabo durante la Segunda Guerra Mundial por el nazismo, Theodor W. Adorno afirmaba, en una frase ya célebre, que escribir poesía después de Auschwitz era un acto de barbarie. La cuestión que ambos teóricos plantean es la de cómo narrar 
el horror cuando las formas tradicionales de narrar se muestran ineficaces frente a la magnitud de las experiencias vividas. Este trabajo parte de la premisa de que existe una relación íntima entre el silencio y el horror, pero que este silencio no es unidimensional ni absoluto, sino que forma parte también del habla de aquellos que han podido articular, aunque fuese de modo fragmentario, la experiencia del horror. A través del análisis de testimonios de mujeres sobrevivientes de la dictadura argentina me interesa pensar como esos silencios "mudos" se articulan en estos testimonios, transformándose en elocuentes.

Existen numerosos silencios en relación con la experiencia dictatorial argentina. Por un lado, el silencio impuesto por un contexto marcado por la censura y la represión, el silencio cómplice de ciertos sectores de la sociedad como la Iglesia católica, y de la sociedad civil que preferían, callar y murmurar por lo bajo "algo habrán hecho" a enfrentarse a los crímenes que se estaban cometiendo en total impunidad. Por otro lado, también hay silencios que pueden leerse como formas de resistencia, como el de aquellos que se negaron a entregar información al sistema represivo ${ }^{1}$. Con el fin de la dictadura y el comienzo de la transición democrática aparecen otros silencios, similares a los que registra Michael Pollak en relación con la experiencia del Holocausto, como el silencio de los sobrevivientes, quienes necesitan integrarse a una sociedad cómplice que todavía los ve como sospechosos, pero también el silencio causado por la muerte, y por la magnitud del horror de la propia experiencia concentracionaria. Frente al silencio mudo de los desaparecidos, y de aquellos sobrevivientes que no pueden hablar, me interesa analizar el silencio que aparece en las narraciones de aquellos que han podido narrar su experiencia a través de testimonios donde tanto las palabras como los silencios se presentan como sumamente importantes a la hora de transmitir estas experiencias traumáticas.

\footnotetext{
${ }^{1}$ Michael Pollak registra varios tipos de silencios en relación con la experiencia del Holocausto, desde quienes regresan a sus lugares de origen y necesitan integrarse a una sociedad cómplice, hasta los silencios ligados a situaciones límite en los campos, mantenidos para evitar culpar a las víctimas.
} 
Rossana Nofal señala que el problema central del testimonio es la presencia de un sujeto en primera persona que se debate entre dos tensiones contradictorias: "la voluntad de reconstruir una experiencia traumática y la voluntad de olvidar" ("Entre el rojo y el negro. Derrotas y victorias de la literatura testimonial argentina" 78). La crítica observa, al igual que Hugo Vezzetti, que mientras los testimonios publicados en Argentina desde 1983 hasta mediados de los años noventa, se enfocaban en la identidad de las víctimas de la represión como sujetos desaparecidos, las producciones testimoniales posteriores cuestionan el lugar del sobreviviente en tanto militante. En este contexto, surge también en las sobrevivientes la necesidad de recuperar la experiencia particular sufrida por estas en tanto mujeres. De este modo, y especialmente a mediados de los noventa, comienza a surgir una producción testimonial femenina que busca reflejar las especificidades de género de la experiencia concentracionaria y carcelaria en manos de las Fuerzas Armadas ${ }^{2}$. La lectura de todo testimonio del horror sugiere que, si bien este tipo de testimonio está impregnado de silencios, los testimonios de detenidas desaparecidas, no intentan eludir sino retomarlos, bordeándolos, construyendo sus relatos a partir de esta relación que se establece entre las palabras y los silencios. En estas narrativas testimoniales los silencios se hacen perceptibles a través de una reflexión o cuestionamiento directo de lo que permanece callado por no poder ser recordado o por no poder ser puesto en palabras. Así como también en el uso de espacios en blanco y puntos suspensivos. A diferencia de los testimonios legales y los testimonios masculinos donde

${ }^{2}$ Me refiero al "boom" de testimonios escritos por mujeres entre los cuales se pueden señalar: M. Actis, G. Aldini, L. Gardekis, M. Lewin, E. Tokar, Ese infierno. Conversaciones de cinco mujeres sobrevivientes de la ESMA , Buenos Aires, Sudamericana, 2001; Noemí Ciollaro, Pájaros sin luz. Testimonios de mujeres de desaparecidos, Buenos Aires, Planeta, 1999; Laura Giussani, Buscada. Lili Massaferro: de los dorados años cincuenta a la militancia montonera, Buenos Aires, Norma, 2005; Adriana Robles, Perejiles. Los otros montoneros, Buenos Aires, Colihue, 2004; Marisa Sadi, Montoneros. La resistencia después del final, Buenos Aires, Nuevos Tiempos, 2004; Gabriela Saidon, La Montonera. Biografía de Norma Arrostito, Buenos Aires, Sudamericana, 2005; Cristina Zuker, El tren de la victoria, una saga familiar, Buenos Aires, Sudamericana, 2003; Nosotras, presas políticas , Buenos Aires, Nuestra América, 2006; La Lopre, Memorias de una presa política, Buenos Aires, Norma. 2006. 
predomina una voluntad de construir una narrativa coherente, tapando de este modo los huecos con otros sentidos, estos testimonios ponen en escena una memoria que se caracteriza por la fragmentación, las pausas, lo que no se dice, así como también lo que se dice a medias, transmitiendo "las verdades presentes en los silencios, en los miedos y en los fantasmas" (Jelin 87).

Los silencios en estas narrativas testimoniales se encuentran cargados de significados, en tanto, lejos de silenciar la experiencia que se busca transmitir, permiten hacer audible esas experiencias. La experiencia del horror, dada su magnitud, desafía al lenguaje y solo puede transmitirse a través de una palabra, un lenguaje que logre vislumbrar algo de aquello que no puede ser dicho. Los testimonios de mujeres hacen hablar al silencio, a través de un dialogo que entiende el silencio no como lo opuesto al lenguaje, sino como parte del lenguaje del trauma. A esto se refieren Munu Actis, Cristina Aldini, Liliana Gardella, Miriam Lewin y Elisa Toker en su testimonio colectivo Ese Infierno: conversaciones de cinco mujeres sobrevivientes de la Esma cuando cuentan que:

En ocasiones alguna se hundía en un silencio melancólico que las otras tratábamos de quebrar sin éxito. Fueron muchos los días en que ese silencio fue de todas, porque nos enmudecía el estupor que nos causaba la confesión de una de nosotras. (32)

A través de estas conversaciones las mujeres ponen a trabajar esos silencios melancólicos, haciéndolos "de todas" y de este modo los transforman. En este contexto, el silencio se presenta también como una forma de comunicación, de unión entre estas mujeres. El lenguaje del trauma debe, indefectiblemente, integrar este silencio, el cual es constitutivo y se encuentra en el centro de la experiencia. No negar el silencio, implica el reconocimiento de que hay ciertos huecos que no pueden, y de hecho no deben, ser tapados. Octavio Paz en su reflexión sobre el lenguaje dice en este sentido: 
Si el lenguaje es la forma más perfecta de la comunicación, la perfección del lenguaje no puede ser sino erótica e incluye a la muerte y al silencio: al fracaso del lenguaje... ¿El fracaso? El silencio no es el fracaso sino el acabamiento, la culminación del lenguaje [...] (119-120)

En el caso de las memorias traumáticas el silencio se presenta como elemento constitutivo del lenguaje. Las palabras funcionan como un marco que tienen como centro aquello que no puede ser dicho, pero que puede ser vislumbrado y, como en el ejemplo citado de las mujeres sobrevivientes de la ESMA, compartido.

\section{Testimonio, saber y transmisión frente a la experiencia del horror}

El testimonio se presenta como sumamente paradójico en tanto su objetivo y justificación es la de documentar fielmente la realidad, pero al estar mediado por la escritura, el lenguaje y la memoria, no puede dejar de construirse como ficción. En la Argentina Operación masacre (1956) del periodista Rodolfo Walsh se presenta como el primer ejemplo de este carácter contradictorio del testimonio: el de valerse muchas veces de la ficción para denunciar verdades históricas (Amar Sánchez 449). La "verdad" que todo testimonio busca representar no puede ser una verdad objetiva ni absoluta, en tanto toda verdad sobre el pasado se construye en el presente y desde la perspectiva de un sujeto. En este sentido la memoria se presenta como opaca, ya que el pasado no es recuperable en su totalidad sino que solo puede ser recuperado de forma fragmentaria. La memoria, como narración, se construye en el presente, a partir de estos fragmentos y esto hace que esta sea vinculada indefectiblemente con lo ficcional. De este modo, el testimonio como construcción narrativa se encuentra en una posición ambivalente, entre la verdad (de los hechos) y la ficción en tanto construcción narrativa. Sin embargo, la 
ficcionalidad que implica el testimonio no se opone a la experiencia del sobreviviente, sino que, por el contrario, deja al descubierto la imposibilidad de representar cualquier experiencia de un modo objetivo. Tanto el silencio como presencia de una ausencia (la de una experiencia que dada su naturaleza traumática no pudo ser incorporada de modo consciente), como la ficción, se hacen necesarios para poder narrar, aunque de modo parcial, esta experiencia se debe a que lo que caracteriza justamente al trauma es la imposibilidad de aquella situación de ser integrada en la narración del yo, en tanto esta altera la coherencia identitaria de este sujeto. Rossana Nofal en su artículo sobre Roberto Walsh demuestra de que modo este autor utiliza la ficción para exponer la verdad de los hechos. Una verdad que sin embargo no puede sino ser subjetiva, ya que el testimonio implica siempre un vínculo entre un individuo y una verdad.

El relato testimonial se incluye en una tradición que deja de lado la creencia de que es posible el testimonio objetivo y que este puede garantizar la vedad en la medida en que es auténtico. Esto implica una transformación en la idea de verdad, y es aquí en donde se encuentran los elementos que constituyen la identidad de género. ("Operación masacre: la fundación mitológica del testimonio" 28)

De este modo, el relato testimonial se distancia del concepto de "verdad" utilizado por el positivismo, que entiende la verdad como "adecuación" entre el intelecto y la cosa. Para el pensamiento positivista que cree en la verdad universal y absoluta, la verdad es el acuerdo entre la mente del hombre y la realidad "exterior" a este. Las polémicas que surgen en relación a la verdad del testigo y la validez de su testimonio se deben a esta concepción de "verdad", y a la necesidad del científico positivista de entender esta como un hecho empírico, en vez de una 
verdad subjetiva $^{3}$. El psicoanalista Dori Laub se refiere precisamente a esto cuando describe la polémica que generó entre los historiadores el testimonio de una sobreviviente, quien afirmó haber presenciado la explosión de cuatro chimeneas de los hornos crematorios durante la rebelión de los prisioneros en Auschwitz, cuando en realidad solo había explotado una chimenea. Frente a las objeciones de los historiadores positivistas quienes ponían en duda la validez de este testimonio Laub responde que:

The woman was testifying, he insisted, not to the number of the chimneys blown up, but to something else more radical, more crucial: the reality of an unimaginable occurrence. One chimney blown up at Auschwitz was as incredible as four. The number mattered less than the fact of the occurrence... The woman testified to an event that broke all compelling frame of Auschwitz, where Jewish armed revolts just did not happen, and had no place. She testified to the breakage of a framework. That was historical truth. (60)

Lo ficcional en este relato, las cuatro chimeneas, representan la exageración, acaso necesaria, para poder describir algo cuya naturaleza era casi imposible e inverosímil, como la posibilidad de una insurrección en Auschwitz. En este sentido, el testimonio cuestiona los límites entre realidad y ficción, ya que para poder retratar lo real tiene que valerse de lo ficcional. Desde el psicoanálisis Laub hace referencia a verdades subjetivas, así como también a los silencios y huecos como partes y manifestaciones de estas verdades. Frente a eventos, como el Holocausto o la dictadura argentina, que ponen en cuestionamiento toda posibilidad de comprensión, cabe indagar por otros significados en relación a la

${ }^{3}$ Tal vez el ejemplo más famoso de este tipo debates en torno a la "verdad" y autenticidad testimonial, lo podamos encontrar en el famoso debate entre el historiador David Stoll y Rigoberta Menchú. Para explorar esta polémica, ver Arias, Arturo. The Rigoberta Menchú Controversy. Minneapolis: University of Minnesota Press, 2001. 
realidad y a la forma de construir conocimiento. Es en este sentido que Lyotard se pregunta por el significado de "Aushchwitz", cuestionando si Auschwitz es acaso únicamente aquello que podemos comprender. Para Lyotard, Auschwitz es un signo que debería ser comprendido pero que desde la lógica del conocimiento no puede ser comprendido. De este modo el silencio se convierte no en olvido o ausencia, sino en un sentido cargado de algo que podríamos tal vez llamar emoción, un sentido que no puede ser entendido por la lógica del conocimiento:

The silence that the crime of Auschwitz imposes on the historians is for everyday people a sign. Signs [...] are not referents to which verifiable significations are attached under the cognitive regime. They indicate that something that should be able to be phrased cannot be in the accepted idioms. (91)

El horror se presenta de este modo para Lyotard como un "signo" que requiere de otras vías de entendimiento que no respondan al conocimiento y a la concepción de "verdad" en el sentido tradicional, sino que busquen leer estos silencios y traten de responder éticamente a estos.

\section{La voz del sobreviviente: Debate en torno al privilegio epistemológico.}

En Tiempo pasado. Cultura de la memoria y giro subjetivo, Sarlo se inserta en este debate acerca de la representación del horror, poniendo en duda la validez de la memoria subjetiva que según ella es producto de una "industria memorialista" que termina, en su consumo y producción masiva, anulando la necesaria posibilidad de reflexión. Todorov, plantea algo similar cuando habla de "los abusos de la memoria" y critica la existencia y exposición de una memoria obsesiva que en su exposición masiva no permite la reflexión o la elaboración productiva de la experiencia: 
Sin duda, todos tienen derecho a recuperar su pasado, pero no hay razón para erigir un culto a la memoria por la memoria; sacralizar la memoria es otro modo de hacerla estéril. Una vez restablecido el pasado, la pregunta debe ser: ¿para qué puede servir, y con qué fin? (12)

Sarlo pone en duda la validez del testimonio en tanto fuente histórica debido a su naturaleza subjetiva sosteniendo que todo relato en primera persona está acechado por "el peligro de una imaginación que se establezca demasiado firmemente en casa" (55). Cuestionando de este modo "los privilegios del yo frente a otros discursos en los que la primera persona esta desplazada y que revelan la necesidad de revisar la transformación del testimonio en icono de verdad" (56). En su celebración de textos de sobrevivientes escritos en tercera persona como el de Pilar Calveiro por su posición crítica y teórica, Sarlo pone en escena su preferencia por una distancia, que según ella, permitiría una reflexión y un análisis objetivo de los hechos. La crítica de Sarlo a lo que ella llama el "giro subjetivo" y personal que aparece con la explosión testimonial, difiere de la posición de Lyotard. Para este el horror (se refiere al caso de Auschwitz) no puede ser analizado ni entendido de ninguna manera, mucho menos desde la distancia. Ya que justamente lo que caracteriza a este evento es la imposibilidad de ser comprendido por medio de los paradigmas y lenguajes de las ciencias. El testimonio del horror no puede sino ser hecho desde este, desde adentro, y desde una memoria que por traumática y por ser ella misma un artificio, una construcción se aleja del discurso científico para hablar desde la fragmentación, la inexactitud y el silencio. Es precisamente desde este lugar que la sobreviviente, ex presa política, Alicia Kozameh, construye su testimonio:

Estuve haciendo serios esfuerzos por recordar algunos episodios. No hubo caso. Es como si se me instalara una sábana entre los ojos y el cerebro. La 
razón de la desmemoria está ahí: en los colores, las formas, la mayor o menor nitidez, los ritmos. (102)

Es esta falta de certeza absoluta en el pasado que distingue al testimonio de la deposición legal, la cual no admite la presencia de este tipo de huecos y fracturas en su relato fáctico. En este sentido, Ricardo Foster sostiene que": "al volverse dato, prueba endeble, material de investigación y confrontación, la palabra del testimoniante se convierte en otra cosa, pierde su estatuto y poco tiene que ver con su primera manifestación (4). De hecho, el testimonio del sobreviviente, a diferencia del testimonio legal, no tiene tanto que ver con la "verdad" de los hechos, sino con el rescate de una voz, hecha también de silencios, y que llama a un nuevo tipo de escucha que se aleje tanto del examen teórico como del judicial:

When considering the contributions of testimonial subjects who have survived the repression, a shift from speaking to listening might prove useful. If we listen, we will realize that, contrary to Sarlo's belief (64-84), many texts $[\ldots]$ do not claim to deliver the truth but just want to be included in the conversation. (Partnoy, "Cuando vienen" 1668)

De este modo, los testimonios de sobrevivientes convocan a una escucha ética, que no se acerque al sobreviviente/testigo para juzgarlo, sino para escucharlo. Al cuestionar la autoridad narrativa de los testigos, privilegiando la voz de teóricos y académicos, Sarlo legitima una concepción del saber y del conocimiento hegemónica que se construye desde los círculos de poder. Y que tradicionalmente se asocia a lo masculino como espacio hegemónico en la

\footnotetext{
${ }^{4}$ Cecilia Vallina, edita Crítica del testimonio. Ensayos sobre las relaciones entre memoria y relato con distintos articulos que entran en debate con el libro de Sarlo, Tiempo pasado. Cultura de la memoria y giro subjetivo.
} 
producción de conocimiento. John Beverly critica a Sarlo en este sentido por privilegiar los criterios disciplinarios de la construcción del saber, que el testimonio amenaza:

Sarlo is concerned both with how testimonio erodes standards of disciplinary authority and boundaries, and how it engenders a new form of 'subjective' politics: solidarity politics, founded on empathy, and identity politics, founded on the gender identity. (74)

En este sentido la posición de Sarlo se asemeja a la del antropólogo David Stoll quien dedico diez años de su carrera buscando pruebas a fin de invalidar y deslegitimar el testimonio de Rigoberta Menchú. No deja de ser curioso el hecho de que todos estos ataques a las voces testimoniales tengan como protagonistas de estas polémicas a mujeres, como Menchú en el caso de Stoll, la mujer sobreviviente de Auschwitz de la que los historiadores positivistas desconfían, y que la crítica de Sarlo coincida con el ya citado boom de testimonios de mujeres sobrevivientes en la Argentina. Todos estos casos presentan una desconfianza y un cuestionamiento de la veracidad de la mujer en su relato. En este sentido, podemos pensar en un vínculo entre el testimonio y lo femenino como espacios de subalternidad pero también de resistencia.

Las limitaciones que el testimonio presenta en tanto reconstrucción del pasado, $\mathrm{y}$ en relación con los saberes hegemónicos, hacen de este un género con potencial revolucionario para desestabilizar las hegemonías del conocimiento donde se inscriben y mantienen las relaciones asimétricas de poder. Por esta razón, son justamente estas limitaciones las que deben ser enfatizadas a fin de poner en cuestionamiento los pilares sobre los cuales se construye el conocimiento como espacio tradicionalmente asociado a lo masculino. Como en el ejemplo de Alicia Kozameh, hacer explícitos los límites y lagunas de la memoria y las dificultades para articular ciertas experiencias, lejos de convertir a estos testimonios en menos legítimos, hacen que estos expongan las formas a 
través de las cuales se construye la historia y los saberes oficiales. En este sentido es que Jean Franco se refiere a que lo que los debates en relación al testimonio ponen en evidencia es una "lucha por el poder interpretativo," lucha que tiene que ver con las epistemologías y las formaciones discursivas. El testimonio como género discursivo pone en cuestionamiento el monopolio interpretativo masculino.

\section{El silencio y la tortura.}

Cathy Caruth afirma que "trauma is not locatable in the simple violent original event in an individual's past, but rather in the way that its very unassimilated nature-the way it was precisely not known in the first instance returns to haunt the survivor later on" (4). El trauma sufrido por el sobreviviente, se presenta como un silencio, una ausencia, un vacío, que sin embargo se hace presente. El sobreviviente, quien se convierte, en oposición con el desaparecido, en el cuerpo que alberga el trauma, es llamado a hacerlo de forma silenciosa, ya que, en la mayoría de los casos la experiencia, la tortura sufrida no ha dejado huellas visibles en el cuerpo del sobreviviente. Y sin embargo, es en estas marcas no visibles donde reside el trauma. Esto, también es paradójico, ya que como resalta Elaine Scarry, la tortura justamente reduce al ser humano a ser pura corporalidad, a su materialidad, sin embargo, al no dejar huellas visibles en el cuerpo del sobreviviente, la experiencia de la tortura se vuelve, de algún modo, invisible. La reducción a la pura corporalidad está asociada a la pérdida de la voz que la tortura implica. La tortura destruye el lenguaje y el acto de habla, y lo hace justamente a través de hacer hablar al torturado:

Mediante el tormento se arrancaba al hombre información y su misma humanidad, hasta dejarlo vacío. La sala de torturas, el quirófano en la jerga concentracionaria, era el lugar donde se operaba sobre la persona 
para producir ese vaciamiento. Era un largo proceso que duraba días, semanas, meses hasta lograr la producción de un nuevo sujeto, completamente sumiso a los designios del campo. (Calveiro 73)

Según Scarry, la tortura consiste en dos partes: la primera, el acto físico, la implementación del dolor físico y la segunda, el acto verbal de la interrogación. De hecho la tortura se justifica en este acto verbal. Sin embargo, la tortura buscaba quebrar a los sujetos, más que obtener información. La sobreviviente Graciela Fainstein en su testimonio expresa este vaciamiento, esta pérdida de identidad, humanidad y voz que la tortura produce:

Grito cuando no me queda nada más, cuando me he vaciado completamente porque he perdido todo, todo lo que soy, todo lo que creía ser y me convierto entonces en un pedazo de carne doliente. (94)

Es importante aclarar que mantener silencio durante la tortura, aunque se presenta como acto de resistencia, no significa necesariamente que el detenido no se haya "quebrado", ni que este sea superior "moralmente" a aquel que dio información. La sobreviviente Teresa Meschiatti dice que a pesar de haber permanecido callada la experiencia de la tortura es devastadora:

A mí me torturaron cinco hombres. Yo...nunca más volví a ser la misma [...] No hay palabras para poder explicar lo que es un campo de concentración. La tortura es un juego donde se establece claramente quien gana y quien pierde. Yo gané: no les di la información que querían [...] pero ellos me ganaron en algo. ( Diana 50)

No se puede juzgar a los sobrevivientes en relación a si estos entregaron o no información como "héroes" o "traidores", ya que esto no sólo es injusto, dado 
que el énfasis tendría que estar en juzgar a sus torturadores, sino que además interpreta la experiencia concentracionaria como si esta pudiera ser simplificada o explicada a través de una serie de conceptos dicotómicos. Dice Pilar Calveiro en este sentido que en los centros clandestinos de detención: "Nada quedó blanco o negro; todo alcanzo raras tonalidades, a veces incomprensibles" (159). Pero lo que me interesa resaltar aquí en relación al silencio inmediato que produce la tortura después del acto de habla (o incluso sin este), es que este es un silencio mudo. Sólo cuando este silencio es "trabajado", compartido y recuperado a través de la palabra es que éste se convierte en otro tipo de silencio que se reconoce como tal, y que por lo tanto no permanece callado, aunque no pueda ser hablado o dicho. De ahí la importancia del testimonio, y de la recuperación de la voz del sobreviviente como testigo de su propia experiencia, una voz que sin embargo, nace del silencio $\mathrm{y}$ enseña al receptor $\mathrm{y}$ al propio sobreviviente en su transformación en testigo, a convivir con este silencio, a no tener que callarlo o taparlo.

Susana Jorgelina Ramus sobreviente y autora de Sueños sobrevivientes de una montonera a pesar de la ESMA en su testimonio explica este proceso a través del cual este silencio es trabajado y convertido en un silencio con el que ella puede convivir, y al que puede rodear y contemplar sin miedo:

[...] porque sé que siempre se está solo y es bueno no necesitar a los demás para tapar el silencio, poder estar conmigo a solas y no entristecerme [...] Ahora que al fin he podido reconciliarme conmigo la perspectiva es diferente. No sé cómo llegué a este momento, los recuerdos del pasado son de mucho sufrimiento, cuando veo mi diario veo cuanto me costó llegar a sentir esto. (69-70)

Poder "estar sola" y en silencio, para esta sobreviviente, significa coexistir y aceptar el silencio de la experiencia traumática. Quiere decir haber recuperado la identidad que fue dañada, durante la experiencia como detenida desaparecida. 
Sin embargo, la identidad que recupera no es la anterior a la experiencia del campo, sino una "nueva" identidad que incorpora esta experiencia traumática.

La ruptura total del narcisismo, la necesaria aceptación de esa imagen rota quebrada estallada en mil pedazos y sin embargo entera porque ya no me avergüenza, es más, la respeto. Por todo lo que sufrió, por todo lo que puso para resistir y vencer a la muerte [...] (Ramus 67)

Aceptar la "imagen rota" supone reconciliarse con los fragmentos, dejar la vergüenza de lado, y reclamar una identidad "entera", hecha de sufrimientos pero también de resistencias. Si la vergüenza actúa como una forma de silenciamiento paralizante, no "avergonzarse" quiere decir recuperar esos silencios, trabajarlos, en el sentido de agregarles valor, a fin de transformar tanto la identidad de la víctima como la de la sociedad.

\section{El silencio y el testigo}

Con respecto a la construcción de la figura del testigo, críticos como Giorgio Agamben se han pronunciado sobre la imposibilidad del testimonio en tanto el verdadero testigo, el testigo integral, es aquel que no sobrevivió la experiencia, y que por lo tanto no puede hablar. El sobreviviente es entonces quien habla por este, por delegación, en nombre del desaparecido. Sin embargo, para Agamben el sobreviviente no puede dar testimonio completo de lo que aconteció porque "la verdad" (es dice la experiencia total y absoluta) se encuentra únicamente en el silencio de quienes vivieron hasta el final esta experiencia y que por lo tanto ya no pueden contarla. De este modo Agamben sostiene que: 
The language of testimony is a language that no longer signifies and that, in not signifying, advances into what is without language [...] To bear witness it is necessary that this senseless sound be, in turn, the voice of something or someone that, for entirely other reasons cannot bear witness. It is thus necessary that the impossibility of bearing witness, the "lacuna" that constitutes human language, collapses giving way to a different impossibility to bearing witness- that which does not have a language. (39)

El testigo-sobreviviente es siempre un testigo incompleto y su testimonio es siempre parcial. Sin embargo, este debe ser articulado para romper con el silencio impuesto por la cámara de gas en Auschwitz y los vuelos de la muerte en el Cono Sur. Lo paradójico en relación al testimonio y su relación con el silencio, es que el testimonio es un acto de habla, una respuesta que se erige con el fin de romper ese silencio impuesto, pero que debido a su naturaleza traumática, el relato de esta experiencia se presenta difuso, lleno de olvidos y silencios. El intento de reconstrucción de toda experiencia traumática, dada la naturaleza de esta que supera los límites del lenguaje, no puede sino estar construido también por interrupciones, huecos y silencios.

Quizás no puedo ser muy objetiva, escribo con el ritmo de mi pasión, de mi dolor [...]. Hay inexactitudes, olvidos involuntarios. No puedo hacerlo de otra manera, se trata de relatar esa historia desde mis vivencias, no pretendo que nadie lo vea como la única verdad, es la mía, no puedo ofrecer otra. (Ramus 36)

Trabajar el silencio implica reconocer la imposibilidad de alcanzar una única verdad. En el fragmento citado vemos como el testimonio más que como prueba fáctica, sirve para dar fe de los procesos de elaboración de los hechos. Es 
subjetivo porque de lo que se trata es de elaborar, a través de la incorporación en la narrativa del yo (aunque sea como como ausencia), algo que hasta ese momento no había podido ser incorporado. Poder poner en palabras el horror, o poner en palabras la imposibilidad misma de esta acción, supone una especie de "cura" en tanto la víctima logra, a través de la narración, colocarse en la posición de testigo y así distanciarse de la posición de objeto, a través del acto de habla. Sin embargo, surge inevitablemente la pregunta acerca de: ¿qué lugar ocupa y cuál es el significado del silencio dentro de estas narraciones? Pero también, ¿Cómo podemos en tanto testigos de lo que se nos narra acercarnos a aquello que queda sin decir?

En relación a la primera cuestión Kelly Oliver se pregunta también sobre la posibilidad del testigo de hablar el silencio:

[B]earing witness to the ways in which one was or is rendered a thing or an object is paradoxical in that things and objects cannot testify. While the act of witnessing itself is a testimony to one's subjectivity, the narrative of oppression tells the story of one's objectification and silence. How, then, can we speak the silence of objectification? (98)

Es precisamente en esa imposibilidad, en ese silencio que reside el lenguaje de la opresión. De este modo la historia de la objetivación o deshumanización sufrida por las detenidas-desaparecidas sólo se puede encontrar en tanto silencio. Pero este silencio no implica parálisis, un punto final sobre la cuestión del horror, sino que plantea la búsqueda constante por encontrar un lenguaje que sí pueda hablar el silencio. Ya que es en esa voluntad, en ese intento que se logran trazar nuevos espacios y voces que rodean y logran reflejar algo de la forma de esa "verdad". Al articular estos testimonios imposibles, inaccesibles en su totalidad, las sobrevivientes abren la posibilidad de compartir el silencio, posibilidad que sólo existe cuando ese otro está dispuesto a escuchar tanto lo que el sobreviviente dice, como lo que no puede decir, o solo se puede decir a medias. 
-¿Te dieron mucho?- me preguntó dubitativa, con cierto pudor.

-No, muy poco. Creo que ni siquiera con la máquina, como explicó el celador, sino solamente con el cable. Es terrible pensar que puede ser infinitamente peor. A él, por ejemplo (se refiere a su compañero) lo reventaron.

-Sí, siempre podría haber sido peor. Pero en definitiva siempre es lo mismo. No interesa cuanto...

Y las dos cambiamos de tema en un acuerdo implícito. (Lo Prete

En este fragmento perteneciente a Memorias de una presa política de Graciela Lo Prete, conocida por sus compañeras como "La Lopre", expone a través de los puntos suspensivos, por un lado, el silencio que sigue al intento de hablar sobre la tortura, y por otro lado, el vínculo de solidaridad que este silencio establece entre las dos presas, quienes pactan sobre este una especie de "acuerdo implícito". De hecho con el tiempo, se crea una gran amistad entre estas dos mujeres, caracterizada justamente por el silencio:

Se fue tejiendo una amistad muy estrecha entre Inés y yo, sobre todo cierta complicidad sin palabras. Nos mirábamos, nos observábamos siempre. Nos mirábamos, nos observábamos siempre. En las conversaciones de grupo nos privilegiábamos la una a la otra eligiéndonos siempre como interlocutor, otras veces mirándonos de reojo para corroborar si la otra estaba atenta, había comprendido o se reía del chiste. (33)

Dori Laub en su trabajo enfatiza la presencia de aquel que presta su oído para compartir el silencio del sobreviviente. Para Laub sin esta presencia no puede existir el testimonio: 
He or she must listen and hear the silence, speaking mutely both in silence and in speech, both from behind and from within the speech. He or she must recognize, acknowledge and address that silence, even if this simply means respect- and knowing how to wait. The listener to trauma needs to know all this, so as to be a guide and an explorer, a companion in a journey onto an uncharted land, a journey the survivor cannot traverse or return from alone. (58-59)

Escuchar los silencios, se convierte en la responsabilidad del lector del texto del sobreviviente. En este sentido, el silencio presente en estos testimonios no remite a la palabra que falta sino a lo que le falta a la palabra. Poniendo de manifiesto las dificultades del lenguaje para describir el horror.

\section{El silencio como lenguaje del horror}

La dificultad- de representar lo inenarrable, no debe llevar a la mudez ante lo sublime, sino al trabajo continuo con aquello que lo enmarca y hace presente como ausencia, como silencio. En este sentido lo que me interesa proponer siguiendo a Elizabeth Jelin quien se refiere a la memoria como un trabajo, en el sentido de algo que está en continua transformación, es que el silencio también debe ser trabajado para que se convierta en un silencio activo y elocuente. Los testimonios deben leerse entonces teniendo en cuenta la estrecha relación que existe entre lo que se dice y lo que no se dice pero se hace presente por omisión, como sucede con ciertas figuras retóricas del lenguaje como: la elisión, el apostrofe y la ironía que reconocen no sólo la existencia de aquello que no se dice, sino que lo convierten en el elemento central del discurso. Trabajar el silencio implica reconocer los huecos y lagunas que se presentan en la memoria, y que dan testimonio de que algo aconteció. En su ensayo poético "Lenguaje e 
imágenes balbuceantes" Sandra Lorenzano hace el intento de conectar imágenes de la guerra y el horror con "palabras de sobrevivencia, palabras derrotadas, palabras de ceniza, palabras para salvarnos [...] palabras porque no hay certezas" (78). Su búsqueda por nombrar el horror, la lleva a reflexionar y a darle un lugar privilegiado al silencio:

También el silencio es imagen del horror. El silencio del desierto sin dioses. El silencio del bosque de Buchenwald del que han huido todos los pájaros. El silencio de las tumbas de humo y aire. El silencio del que sabe que no hay testimonio posible. (78)

La verdad de la experiencia del horror sólo puede ser dicha a través de la palabra que incluya el silencio de aquello que no puede ser dicho. La editora y entrevistadora de Mujeres Guerrilleras Marta Diana decide en vez de borrar estos silencios, hacerlos presentes. Los silencios en los testimonios que esta autora recolecta se presentan como claves para transmitir el horror. Haciendo referencia a los casetes que recibía y transcribía de una de las sobrevivientes que dan testimonio en su texto Diana cuenta:

Aquí hubo un largo silencio y pensé por un momento que terminaba ahí. Avance la cinta. No terminaba, ella se había quedado callada. Cuando siguió, la voz tenía una entonación extraña. Recuerdo que experimenté una tensión insoportable a medida que escuchaba las palabras lentas y cortadas por pausas. (mi énfasis 50 )

Diana como oyente y destinataria de estos relatos, se ve obligada a hacernos testigos de su experiencia como testigo del trauma. La autora enfatiza que es en esas "pausas", en esa voz quebrada, que logra experimentar ella misma el trauma como "tensión insoportable". De este modo Diana nos permite concluir 
que si el trauma es transmisible este lo es en sus pausas, en sus silencios. Los testimonios deben leerse entonces teniendo en cuenta la estrecha relación que existe entre lo que se dice y lo que no se dice pero se hace presente por omisión, como sucede con ciertas figuras retóricas del lenguaje como: la elisión, el apostrofe y la ironía que reconocen no sólo la existencia de aquello que no se dice, sino que lo convierten en el elemento central del discurso. En los testimonios de mujeres hay una sobreabundancia de puntos suspensivos, de frases y oraciones no terminadas que llevan al lector a tratar de dilucidar tanto lo que se dice como lo que se deja en suspenso. En The Little School de la sobreviviente Alicia Partnoy el silencio se presenta como parte imprescindible de su testimonio. Este testimonio, como muchos otros, articula imágenes (en este caso dibujos hechos por la madre de la sobreviviente), palabras, junto a espacios en blanco que dan cuenta del silencio como parte del lenguaje del horror, pero sobre todo es en el uso y frequencia de la figura de la elipsis que el silencio se hace audible. Recordando un poema que solía cantarle a su hija Partnoy escribe:

This little poem soothed you when you cried; you went to sleep listeing to it...I've repeated it for a whole day but I still can't sleep.... I won't see you again...The electric prod on my genitals....Trapped, like the little from.... "but we hear him all the time".... (93)

De modo similar, en el ya citado caso de la mujer sobreviviente que atestiguó haber visto cuatro chimeneas explotar en Auschwitz, Laub enfatiza que el silencio que la mujer guarda sobre su participación como miembro de uno de los Sonderkommandos dedicado a recolectar los objetos de las personas asesinadas en la cámara de gas, es clave para entender su testimonio. Laub critica a los historiadores quienes en su busqueda por la verdad empírica no logran escuchar realmente al sobreviviente: 
The historians could not hear, I thought, the way in which her silence was itself part of her testimony, an essential part of the historical truth she was precisely bearing witness to. (62)

Laub plantea la importancia de una escucha activa, que no busque reconocer y legitimar lo que ya sabe, sino que escuche desde la posición del nosaber, de escuchar algo por primera vez. De este modo, es que el testimonio del trauma pone en cuestionamiento las verdades y certezas anteriores a las que estos testimonios se enfrentan.

\section{Género y silencio}

No me parece que sea casualidad el hecho de que sea en los testimonios de mujeres donde más evidente se hacen estos silencios. Esto se debe a que la mujer históricamente ha ocupado el lugar del silencio. La mujer entonces pareciera estar en condiciones de hablar el silencio no solo porque ella misma ha sido desde siempre silenciada, sino también porque su condición femenina la ha hecho “trabajar” el silencio, re significándolo y adaptándolo a sus propias necesidades. La relación de la mujer con el silencio le permite construir una relación con éste, que no se base en la negación, sino que acepte el silencio como condición, como punto de partida. La asociación entre la mujer y el silencio se encuentra tanto en el discurso patriarcal como en el discurso feminista. Dentro del sistema patriarcal el silencio es la forma a través de la cual se oprime a la mujer. La mujer dentro de este sistema se ve obligada a silenciar sus deseos, su sexualidad y su cuerpo. Por

otro lado, la crítica feminista francesa ha reivindicado el silencio como parte de una "escritura femenina" que transgrede el discurso patriarcal, haciendo hincapié en los silencios que se esconden detrás o entremedio de las palabras, los cuales interrumpen el lenguaje patriarcal produciendo una emoción diferente. 
En su análisis acerca de las distintas estrategias que la mujer utiliza para lograr agencia, Josefina Ludmer analiza la respuesta que Sor Juana a Sor Filotea crea para poder hablar y resistir desde una posición de subordinación y marginalidad. Ludmer ve en el uso del silencio que hace Sor Juana, al cual como mujer es reducida, una de las "tretas del débil", un espacio de resistencia ante el poder opresor:

La escritura de Sor Juana es una vasta máquina transformadora que trabaja con pocos elementos [...] saber, decir, no. Modulando y cambiando de lugar cada uno de ellos en un arte de la variación permanente, conjugando los verbos y transfiriendo la negación [...] Decir que no se sabe, no saber decir, no decir que se sabe, saber sobre no decir: esta serie liga los sectores aparentemente diversos del texto. (48)

De este modo, Sor Juana, desde su posición marginal como mujer, convierte el silencio en palabra. De modo similar, Doris Sommer en su análisis del testimonio de Rigoberta Menchú analiza los silencios presentes en su testimonio, para Sommer "estas protestas audibles de silencio" son estratégicas en tanto a través de estas, Menchú logra comunicar la imposibilidad por parte del lector de poder acceder por completo a este testimonio. Menchú hace visibles estos silencios, para dejar en claro que hay verdades, secretos en su testimonio que no pueden ser contados y que el lector debe romper con la ilusión de que la experiencia del horror que le es comunicada puede ser comprendida en su totalidad. Según Sommer, Menchú nos está haciendo una advertencia en relación con estos secretos: "We could never know them as she does, because we would inevitably force her secrets into our framework" (246). De este modo el silencio se convierte en una estrategia por medio de la cual Menchú le niega al lector la posibilidad de identificación y de fácil empatía. El lector se encuentra en otra posición, que no es la posición subalterna, y es desde esta posición que es interpelado por Menchú. En este sentido, a través de este silencio deliberado, 
Menchú establece una relación con el "otro" (el lector) basada en el reconocimiento de la diferencia.

La importancia de escuchar los silencios es para la feminista Luce Irigaray indispensable para poder establecer un diálogo y poder relacionarse éticamente con el otro. En su libro Sharing the world Irigaray sostiene:

It is thanks to silence that the other as other can exist or be, and the two be maintained. Relations between two different subjectivities cannot set up starting from a shared common meaning, but rather from a silence [...] Entering into comunication requires the limits, always effective, of a unique discourse, access to a silence thanks to which another world can manifest itself and take place. (5)

Irigaray llama a entablar relaciones que reconozcan las diferencias, resaltando la importancia del silencio como requisito fundamental de reconocimiento y diálogo con un otro. Todo diálogo existoso debe incluir necesariamente un respeto por los silencios "It is recognizing the neccesity of something unspeakable and its preservation that allows an exchange of words between two different subjects" (5). Los testimonios femeninos al hacer visibles los silencios, poniéndolos en el centro de la comunicación, establecen un dialogo que sirve para pensar nuevas formas de relacionarse entre sujetos que ocupan distintas posiciones de poder.

\section{Nuevas subjetividades: Testimonios jurídicos vs testimonios femeninos}

Todo testimonio implica un diálogo que incluye a quien escucha, $\mathrm{y}$ muchas veces pregunta (como en el caso de una entrevista), como participante activo. La presencia de este otro que escucha activamente, es indispensable para que exista testimonio: "the absence of an addresable other, and other who can 
hear the anguish of one's memories and thus affirm and recognize their realness, annihilates the story" (Laub 68). Es precisamente a través de dar testimonio frente a un "otro" que escucha que se realiza la transformación de la "víctima" en "testigo". Elisa Tokar, sobreviviente de la ESMA, dice que solo dejo de sentirse una víctima después de su declaración.

Después de que nos liberaron también seguimos siéndolo. Quizás vos dejaste de ser un desaparecido en el momento en que declaraste. Yo hasta que pude declarar, en un organismo de derechos humanos, diez años después de mi liberación, seguí siéndolo, al menos para mí misma. (85)

Solo a través de dar testimonio ella puede dejar de ser una "desaparecida", una persona sin identidad. Ser desaparecido significa no tener identidad frente al Estado, pero tampoco, como dice Tokar, frente a uno mismo ${ }^{5}$. El corrimiento de la víctima hacia la posición del testigo, le permite existir como ente, a través del reconocimiento de su subjetividad y saber. Kelly Oliver afirma en este sentido que "witnessing enables the subject to reconstitute the experience of objectification in ways that allow her to reinsert subjectivity into a situation designed to destroy it" (mi énfasis 98).

Oliver usa el pronombre femenino "her", justamente para apuntar que la posición de testigo no debe borrar la marca genérica, sin embargo, en el caso de la Argentina, el testigo se presenta como masculino, de hecho no existe la forma femenina de esta palabra en el español. El "testigo" es masculino en tanto se refiere a la condición humana sin distinciones genéricas. Esto explica porque

\footnotetext{
${ }^{5}$ Sobre este aspecto Pilar Calveiro destaca que en los campos se evitaba toda mención a la humanidad del prisionero. Por lo general, "no se hablaba de personas, gente, hombres, sino de bultos, paquetes, a lo sumo subversivos, que se arrojan, se van para arriba, se quiebran" (42). El uso de este lenguaje sustituto demuestra para Calveiro, por un lado la deshumanización de las víctimas, pero también "cumple con el objetivo "tranquilizador" que inocentiza las acciones más penadas por el código moral de la sociedad como matar y torturar" (42).
} 
recién después de 35 años y muchísimo esfuerzo se esté empezando a tener en cuenta la violencia específica de género dentro de los centros clandestinos.

De este modo, cuando las mujeres son invitadas a dar testimonio, a convertirse en testigos a través de sus testimonios jurídicos, esta invitación a construir y reconocer su subjetividad, sin embargo, mutila una parte importante de la identidad y experiencia de estas mujeres como tales. Como destaca Ana Forcinito en su análisis sobre el testimonio y lo femenino:

En el caso de las mujeres, sometidas no sólo al fantasma interpretativo de la traición sino además condenadas dentro del imaginario heterosexista dentro y fuera del centro clandestino, la convocatoria oficial a testimoniar se abre como una promesa a poder contar una historia, pero como una promesa parcial puesto que se cercenan las instancias que tienen que ver con la violencia de género. (131)

De este modo, el paso de desaparecido a testigo, dentro del marco jurídico del Estado patriarcal, si bien supone un reconocimiento por parte del Estado hacia la mujer sobreviviente como sujeto, al no reconocer su identidad de género, esta re-humanización se torna incompleta, parcial. Las sobrevivientes hacen hincapié en la necesidad, frente a la ceguera de género que el testimonio jurídico supone, de dar testimonios y construir sus subjetividades en tanto mujeres.

Durante un tiempo estuvimos convencidas de que había sido suficiente declarar ante la Justicia [...]Pero todas sabíamos que habíamos vivido otro tipo de historias, no contadas todavía [...]Recordarlas es incómodo... Son historias difíciles de decir. Provocan angustia, reavivan dolores. Resolvimos ser sólo mujeres en el grupo, porque, para nosotras, haber pasado por el Campo tuvo tintes especiales vinculados con el género: la 
desnudez, las vejaciones, el acoso sexual de los represores, nuestra relación con las compañeras embarazadas y sus hijos. (32)

El hecho de que las violaciones y otras vejaciones específicamente de género fueran ignoradas o no tenidas en cuenta, es clave para entender la ceguera en relación al género presente en una sociedad todavía sexista y patriarcal. Es dentro de este contexto que las mujeres deben reconstruir su identidad. Recién después de 35 años, se empiezan a juzgar las violaciones sistemáticas de las que estas mujeres fueron víctimas como un delito de lesa humanidad y no como una forma más de tortura. El lugar de la mujer dentro de esta sociedad patriarcal y sexista coloca a la mujer como víctima en el lugar de la duda, objeto de sospechas de haber sido ella la responsable del delito del que fue víctima. Esto lleva, por un lado, a que la mujer no denuncie esta experiencia, y por otro lado, a que estos crímenes sexuales no sean entendidos como tales por la ley.

En los centros clandestinos las mujeres detenidas-desaparecidas eran tratadas de "putas" y violadas sistemáticamente por no responder al sistema de género hegemónico vigente ${ }^{6}$ :

Y me respondían, como todas las putas montoneras vivís en una pensión. Esas palabras puta montonera durante mi tortura y los días siguientes fueron una constante, las escuché todo el tiempo. (Actis et al 74)

${ }^{6}$ Prueba de hasta que punto el sistema concentracionario reproducía las estructuras patriarcales vigentes en la sociedad es la implementación de un proceso de recuperación por parte de los militares a través del cual las mujeres fueran "recuperadas" a fin de ser re-insertadas en la sociedad. Una de las mujeres sobrevivientes entrevistada por Marta Diana en su libro que recopila testimonios de ex-militantes cuenta hasta que punto este tenía que ver con las normas de género dominantes:

En la ESMA, el proceso de "recuperación" de las mujeres estaba centrado en la explotación de nuestros sentimientos femeninos. Una demostraba estar más "recuperada" en relación directa al interés que demostrara por vestirse, arreglarse, tener modales suaves, etc. (151) 
Las mujeres eran también llevadas en contra de su voluntad, ya que no tenían voluntad ahí adentro, a cenar a bailar por sus captores, lo cual representa también formas de violencia de género que deben ser tomadas en cuenta y sancionadas como tales. El hecho de que en la actualidad las violencias específicas sean tomadas en cuenta como violencias de género se presenta como un avance, una esperanza de que dentro de los testimonios jurídicos, la mujer, por fin, tener una voz propia como mujer. De hecho, no es casualidad que la abogada que luchó por el reconocimiento de la violencia sexual como un crimen de lesa humanidad, Carolina Varsky, sea ella misma una mujer. Varsky recuerda que su inquietud por el tema surgió en el 2007 cuando una testigo relató que la habían violado, y lloró desconsoladamente. "Nadie supo qué hacer con eso, ninguno de los operadores judiciales, y yo pensé que debía hacerse algo al respecto", relató la abogada $^{7}$. (Página 12).

Varsky decidió hacer algo con ese llanto, demostrando de ese modo que de lo que se trata, a fin de devolver a la víctima su condición humana, es de escuchar cada testimonio no para probar su utilidad o para que se convierta en una estadística, en un número más, en una prueba, sino que se debe escuchar lo único, lo particular, lo que no encaja dentro de los cánones, lo que se mantiene en silencio o se transforma en llanto. Ese es el tipo de escucha que los testimonios de mujeres analizados en este trabajo buscan a fin de poder reconstruir sus subjetividades como testigos, como mujeres y como personas. En este sentido, frente al silencio del horror, los testimonios de mujeres plantean la posibilidad de abordar estos a través de un dialogo que incluya tanto las palabras como los silencios. Transformando el silencio paralizador en un silencio que pueda ser transmitido y compartido como presencia de una ausencia.

\footnotetext{
${ }^{7}$ Varsky cree que hoy las dificultades más grandes no están en las testigos y sobrevivientes sino en quienes deben hacerse cargo desde el sistema judicial. "Hay una dificultad de escuchar estas denuncias, que es sobre lo que más tenemos que trabajar, el trabajo con las víctimas ya se viene haciendo, desde la apertura del proceso", apuntó (Tessa, 2009: s/n).
} 
La posibilidad que el testimonio jurídico ha abierto para las sobrevivientes al convertirse de víctimas a testigos, debe ser re-formulada para que esta transformación incluya también la diferencia de género. Si la experiencia en los centros clandestinos estuvo fuertemente marcada por concepciones de género dominantes, la diferencia sexual debe entrar en los debates por la memoria y la democracia. Las mujeres solo podrán re-construir sus subjetividades en tanto mujeres a través de la posibilidad de dar testimonio de las vejaciones sufridas ante una sociedad que este dispuesta a escucharlas, respetando sus silencios.

Los silencios de las experiencias traumáticas no deben quedar callados, sino que deben ser transmitidos, por un lado, para que de este modo se haga justicia, pero también para que las víctimas puedan construir nuevas subjetividades a través de "trabajar" los silencios, incorporándolos a esta nueva subjetividad, hecha de lo que se dice y lo que no puede ser articulado, pero que puede ser sentido en esos silencios presentes en los puntos suspensivos, las elipsis y las palabras que dan cuenta de las dificultades de narrar o recordar esas experiencias. Se trata de trabajar el silencio a fin de convertirlo no en un punto final, sino en un disparador de lenguajes y sensaciones que intenten acercarnos y hacernos testigos de estas experiencias del horror. Los testimonios de mujeres rodean el silencio, lo enfrentan, trazando lenguajes y espacios adyacentes que permiten entablar un dialogo basado en el respeto y la empatía.

\section{Bibliografía}

Actis, Munú et al. Ese infierno: conversaciones de cinco mujeres sobrevivientes de la ESMA. Buenos Aires: Sudamericana, 2001.

Agamben, Giorgio. Homo Sacer: Sovereign Power and Bare Life. Standford: Standford University Press, 1998. 
Benjamin, Walter. El narrador (1936). Editorial Taurus, Madrid 1991.

Calveiro, Pilar. Poder y desparición: los campos de concentración en Argentina. Buenos Aires: Colihue, 1998.

Caruth, Cathy. Trauma: Explorations in Memory. Baltimore y London: The John Jopkins University Press, 1995.

Cubilié, Anne. Women Witnessing Terror: Testimony and the Cultural Politics of Human Rights. 1st ed. New York: Fordham University Press, 2005.

Diana, Marta. Mujeres guerrilleras. La militancia de los setenta en el testimonio de sus protagonistas femeninas. Buenos Aires: Planeta, 1997.

Doris, Sommer. "Sin secretos". La voz del otro: Testimonio, subalternidad y verdad narrativa" John Beverley y Hugo Achugar, eds. Lima: Latinoamericana Editores, 1993.

Fainstein, Graciela. Detrás de los ojos. Buenos Aires: Icaria, 2006.

Felman, Shoshanna y Laub Dori. Testimony: Crises of Witnessing in Literature, Psychoanalysis and Historty. New York: Routledge, 1991.

Forcinito, Ana. Los umbrales del testimonio: Entre las narraciones de los sobrevivientes y las señas. Madrid: Iberoamericana, 2012.

Forster, Ricardo "El imposible testimonio: Celan en Derrida". Pensamiento de los Confines. 8 (2000): 77-88. Buenos Aires.

Irigaray, Luce. Sharing the World. London-New York: Continuum, 2008.

Jara, René. "Prólogo", en René Jara y Hernán Vidal (eds.), Testimonio y literatura. Minneapolis: Institute for the Study of Ideologies and Literature, 1986.

Jelin, Elizabeth. Memorias de la Represión: Los trabajos de la memoria. Madrid: Siglo XXI, 2002.

Kaplan, Ann. Trauma Culture: The Politics of Terror and Loss in Media and Literature. New Brunswick, NJ: Rutgers University Press, 2005.

Kozameh, Alicia. Pasos bajo el agua. Córdoba: Alción, 2002. 
Lo Prete, Graciela. Memorias de una presa politica (1975-1979). Buenos Aires: Norma, 2006.

Lorenzano, Sandra. Lenguaje e imagenes balbuceantes:Universidad Nacional Autónoma de México: 2006. 25. 76-80

Ludmer, Josefina. "Tretas del débil." La sartén por el mango: Encuentro de escritoras latinoamericanas. Ed. Patricia Elena González. Puerto Rico: Huracán, 1985.

Lyotard, Jean-Francois. Le Differend. Paris: Minult, 1984.

Nofal, Rossana. "Entre el rojo y el negro. Derrotas y victorias de la literatura testimonial argentina" Estudios. Revista del Centro de Estudios Avanzados". Córdoba: 2009. 21. 78 - 93.

----. Operación masacre: la fundación del testimonio. Stockholm Review of Latin American Studies. "Memorias de la represión en Argentina y Uruguay: narrativas, actores e instituciones". Estocolmo: 2011. 7. 59 - 70.

Oliver, Kelly. Witnessing: Beyond Recognition. Minneapolis and London: University of Minnesota Press, 2001.

Partnoy, Alicia. "Cuando vienen matando: On Prepositional Shifts and the Struggle of Testimonial Subjects for Agency." PMLA. 121:5. October 2006, 1665-1669.

Paz, Octavio. Obras completas. Tomo 10. Ideas y costumbres II. Usos y símbolos. México D.F.: Fondo de Cultura Económica, 1996

Pollak, Michael. Memoria, olvido, silencio. La Plata: Al Margen, 2006.

Ramus, Susana Jorgelina. Sueños sobrevivientes de una montonera, a pesar de la ESMA. Buenos Aires: Colihue, 2000.

Tessa, Sonia. "El testimonio de mujeres violadas durante la dictadura", en Página 12,9 de octubre de 2009.

Todorov, Tzvetan. Los Abusos de la Memoria. Barcelona: Paidós Ibérica, 2000. 
Sánchez, Ana María Amar. El relato de los hechos. Rodolfo Walsh: testimonio y Escritura. Rosario: Beatriz Viterbo Editora, 1992.

Sarlo, Beatriz. Tiempo pasado. Cultura de la memoria y giro subjetivo. Una discusión. Buenos Aires: Siglo XXI, 2005.

Scarry, Elaine. The Body in Pain: The Making and Unmaking of the World. New York: Oxford University Press, 1985. 